\title{
Equilibrium, disequilibrium, and crystal growth in basaltic magmas
}

\author{
M. E. HARTLEY ${ }^{1} *$ F. ARzILli ${ }^{1}$, M. POLACCI ${ }^{1}$, G. LA
} SPINA ${ }^{1}$, M. BURTON ${ }^{1}$, N. LE GALL ${ }^{2}$, J. MACLENNAN ${ }^{3}$

${ }^{1}$ Department of Earth and Environmental Sciences, University of Manchester, UK (*correspondence:

margaret.hartley@manchester.ac.uk)

${ }^{2}$ Department of Mechanical Engineering, University College London, UK

${ }^{3}$ Department of Earth Sciences, University of Cambridge, UK

Magma crystallization exerts fundamental controls on magma rheology and hence eruption style. Crystallization is typically modelled assuming that mineral-melt equilibrium is maintained. However, at the onset of crystallization, conditions may be far from equilibrium, particularly in volcanic conduits where pressure, temperature and dissolved volatile contents are changing rapidly.

We have conducted in situ synchrotron X-ray tomography experiments to image crystal nucleation and growth in real time. Our starting material is a glass synthesized by melting basaltic scoria from the 2001 eruption of Mt Etna. Oneatmosphere cooling experiments on anhydrous starting materials simulate cooling in natural basalt lava flows [1]. Under all cooling regimes we observe that crystal nucleation and growth occur in pulses. At high undercooling clinopyroxene exhibits both heterogeneous and homogeneous nucleation [1]. We observe platy, skeletal and swallowtail plagioclase morphologies, similar to textures found in the products of basaltic Plinian eruptions [2]. All the cooling regimes generate plagioclase compositions of $\sim \mathrm{An}_{64-74}$, similar to natural plagioclases from the Etna 2001 erupted products. At high undercooling, clinopyroxene compositions closely match the natural samples, but clinopyroxenes grown under continuous rates of cooling have much lower $\mathrm{Mg}$ numbers indicating a later appearance of clinopyroxene on the basalt liquidus.

We also conducted coupled decompression and cooling experiments on hydrous starting materials to simulate concurrent crystallization and vesiculation in the upper $\sim 1-2$ $\mathrm{km}$ of a volcanic conduit. We observe initial growth of blocky clinopyroxene, followed by the growth of swallowtail dendrites from the crystal corners as cooling and decompression proceed. Our experiments shed new light on disequilibrium crystallization in basaltic magmas, and facilitate interpretation of mineral compositions and textures in basaltic eruption products.

[1] Polacci et al. (2018) Scientific Reports 8:8377.

[2] Arzilli et al. (2019) Nature Geoscience 12:1023-1028. 